\title{
Radical Cations from Dicyclopropylidenemethane and Its Octamethyl Derivative
}

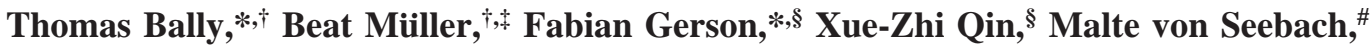 \\ Sergei I. Kozhushkov," Armin de Meijere,,$\| l$ Vsevolod I. Borovkov, ${ }^{*, \perp}$ and Pavel A. Potashov ${ }^{\perp}$ \\ Department of Chemistry, University of Fribourg, Switzerland, Department of Chemistry, University of Basel, \\ Switzerland, Institut für Organische und Biomolekulare Chemie, Georg-August-Universität Göttingen, Germany, \\ and Institute of Chemical Kinetics and Combustion, Russian Academy of Sciences, Siberian Branch, \\ Novosibirsk, Russia
}

\begin{abstract}
The radical cations of dicyclopropylidenemethane (2) and its octamethyl derivative (2-Me $\left.\mathbf{C}_{8}\right)$ are prone to rearrangements into those of (2-methylallylidene)cyclopropane (2a) and its octamethyl derivative $\left(\mathbf{2 a}-\mathbf{M e}_{8}\right)$, respectively, by opening one three-membered ring. In contrast to the radical cations of bicyclopropylidene (1) and its octamethyl derivative $\left(\mathbf{1}-\mathrm{Me}_{8}\right), \mathbf{2}^{\cdot+}$ and $\mathbf{2}-\mathrm{Me}_{8}{ }^{\bullet+}$ are stable to opening of the second ring, because in this case the resulting species would be a non-Kekule hydrocarbon with a quartet ground state. Similarly to $\mathbf{1}$, octamethyl substitution in $\mathbf{2}$ promotes the tendency to rearrangement. Thus, ESR and ENDOR studies indicate that the primary radical cation $\mathbf{2}^{\cdot+}$, which is formed upon $\gamma$-irradiation of $\mathbf{2}$ in a $\mathrm{CFCl}_{3}$ matrix at 77 $\mathrm{K}$, does not rearrange up to $150 \mathrm{~K}$. On the other hand, when $2-\mathrm{Me}_{8}$ is treated in the same way, only the rearranged radical cation $\mathbf{2} \mathbf{a}-\mathrm{Me}_{8}{ }^{\bullet+}$ can be observed and characterized by its ESR and ENDOR spectra. Nevertheless, the existence of the two "missing" species, $\mathbf{2} \mathbf{a}^{\bullet+}$ and $\mathbf{2}-\mathbf{M e}_{8}{ }^{++}$, is revealed by other methods. According to UV and IR studies, $\mathrm{X}$ irradiation of $\mathbf{2}$ in an Ar matrix leads directly to the ring-opened radical cation $\mathbf{2 \mathbf { a } ^ { \bullet + }}$. Moreover, magnetic field effects on the decay of fluorescence, which appears upon recombination of the radical anion of $p$-terphenyl with a radical cation generated from $2-\mathrm{Me}_{8}$ in liquid octane, strongly suggest that $2-\mathrm{Me}_{8}{ }^{+}$(and not $\mathbf{2 a}-\mathrm{Me}_{8}{ }^{+}$) is formed initially. From the temperature dependence of the decay, the activation energy of the ring-opening process $\mathbf{2}-\mathrm{Me}_{8}{ }^{\bullet+} \rightarrow \mathbf{2} \mathbf{a}-\mathrm{Me}_{8}{ }^{\bullet+}$ is estimated. The radical cations $\mathbf{2 a}^{\mathbf{}^{+}}$and $\mathbf{2} \mathbf{a}-\mathrm{Me}_{8}{ }^{+}$are formally distonic with the spin residing in the allylic moiety and the charge accommodated on the central carbon atom of the allene $\pi$-system. The intact cyclopropylidenemethylidene moiety assumes a "bisected" conformation, thus favoring an optimal interaction with the positively charged center on the $\pi$-system.
\end{abstract}

\section{Introduction}

By now, it is common knowledge that the type of bonding in three-membered rings is unique and profoundly different from those in larger rings and in acyclic analogues. ${ }^{1,2}$ The pronounced tendency of cyclopropane derivatives to undergo ring-opening reactions is a consequence of the ring strain associated with the unique geometry and bonding. ${ }^{3-5}$ Although the chemical behavior of reactive intermediates derived from cyclopropanes, such as anions, cations, radical anions, and radical cations, has been studied in great detail computationally as well as experimentally, ${ }^{6-8}$ it still attracts considerable interest.

As previously reported, ${ }^{9-11}$ ionization of bicyclopropylidene (1) $)^{12-14}$ in a $\mathrm{CFCl}_{3}$ matrix by $\gamma$-rays at $77 \mathrm{~K}$ led to the primary radical cation $\mathbf{1}^{\circ}$, which, above $100 \mathrm{~K}$, underwent spontaneous opening of both rings to yield the radical cation of tetramethyleneethane $\left(\mathbf{1 b}^{\bullet+}\right)$, a positively charged biallyl. Such a ring opening occurred even more easily in ionized octamethylbicyclopropylidene $\left(\mathbf{1}-\mathrm{Me}_{8}\right)$, as this compound rearranged in a $\mathrm{CFCl}_{3}$ matrix already at $77 \mathrm{~K}$ to the radical cation of octamethyltetramethyleneethane $\left(\mathbf{1 b}-\mathrm{Me}_{8}\right) .{ }^{11}$ In both cases, formation of an

* Corresponding authors. E-mail: (T.B.) Thomas.Bally@unifr.ch; (F.G.) Fabian.Gerson@unibas.ch; (P.A.B.) borovkov@ns.kinetics.nsc.ru.

University of Fribourg.

$\doteqdot$ Present address: BUWAL, 3003 Bern, Switzerland.

$\S$ University of Basel.

\# Georg-August-Universität Göttingen.

"E-mail: ameijer1@gwdg.de.

${ }^{\perp}$ Russian Academy of Sciences, Siberian Branch.

\section{SCHEME 1}

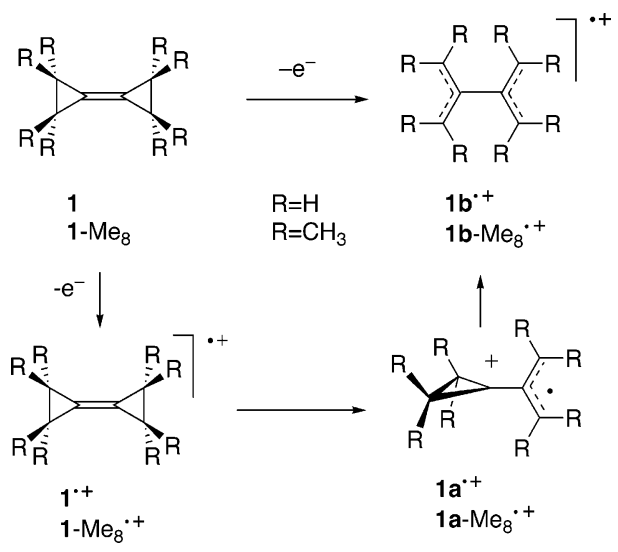

intermediate radical cation $\mathbf{1 a}^{\bullet+}$ or $\mathbf{1 a}-\mathrm{Me}_{8}{ }^{\bullet+}$ with only one opened ring was never observed. These findings were rationalized on the basis of quantum-mechanical calculations which predict that these intermediate species should be short-lived, because they are separated from $1 \mathbf{b}^{\bullet+}$ and $\mathbf{1 b}-\mathrm{Me}_{8}{ }^{\bullet+}$, respectively, by very low energy barriers ${ }^{11}$ (cf. Scheme 1).

In dicyclopropylidenemethane $(2)^{15-17}$ and its octamethyl derivative (2-Me 8 , cf. Scheme 2), ${ }^{16}$ the two cyclopropylidene moieties are linked by an allene and not by an ethene $\pi$-system. As a consequence, they are orthogonal with respect to one another (the symmetry is $D_{2 d}$ instead of $D_{2 h}$ ), and they are kept at a longer distance $\left[2.586(4) \AA\right.$ in $2-\mathrm{Me}_{8}{ }^{16}$ vs $1.304(2) \AA$ in 


\section{SCHEME 2}
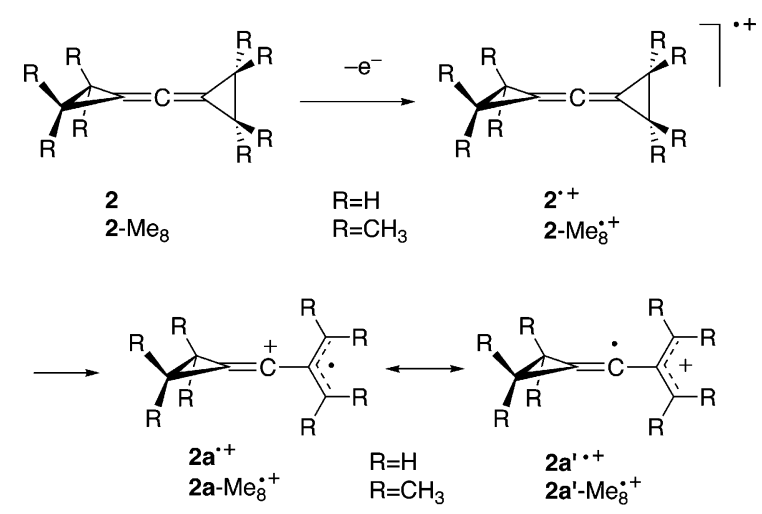

$\mathbf{1}^{12}$ at $200 \mathrm{~K}$ ]. It was interesting to investigate the effect of these structural and electronic changes on the coupling between the two cyclopropylidene moieties and, hence, on the behavior of the ionized molecules. The present paper reports on the results of the pertinent studies.

\section{ESR and ENDOR Spectra}

Dicyclopropylidenemethane (2) was ionized by $\gamma$-rays $\left({ }^{60} \mathrm{Co}\right.$ source) in a $\mathrm{CFCl}_{3}$ matrix at $77 \mathrm{~K}$ and was studied by ESR spectroscopy up to $150 \mathrm{~K}$. The paramagnetic species thus obtained exhibited a hyperfine pattern consisting of five components spaced by $1.96 \pm 0.03 \mathrm{mT}$ and arising from four equivalent protons (Figure $1 ; g=2.0030 \pm 0.0001$, peak-topeak-distance $\left.\Delta B_{\mathrm{pp}}=0.34 \mathrm{mT}\right)$. The signals in the corresponding ${ }^{1} \mathrm{H}$-ENDOR spectrum (not shown; $v_{\mathrm{H}}=14.56 \mathrm{MHz}$ ) had an anisotropic shape. Those in the ranges $12-14$ and $41-43$ $\mathrm{MHz}\left(\left|a_{\mathrm{H}} / 2\right| \pm v_{\mathrm{H}}\right)$ confirmed that the major four-proton coupling constant has an isotropic value $\left|a_{\mathrm{H}}\right|=55.0 \pm 0.5 \mathrm{MHz}$ or $1.96 \pm 0.02 \mathrm{mT}$, while further signals at $12-14$ and $15-17$ $\mathrm{MHz}\left(v_{\mathrm{H}} \pm\left|a_{\mathrm{H}} / 2\right|\right)$ indicated a second, smaller coupling constant $\left|a_{\mathrm{H}}\right|$ with the isotropic value of $3.5 \pm 0.2 \mathrm{MHz}$ or $0.125 \pm 0.005$ $\mathrm{mT}$, which is certainly due to the four remaining protons.

The paramagnetic species obtained from octamethyldicyclopropylidenemethane $\left(\mathbf{2}-\mathrm{Me}_{8}\right)$ under the same conditions gave rise to a pattern of 13 hyperfine components. These components were spaced by $1.40 \pm 0.03 \mathrm{mT}$ and are diagnostic of an interaction with 12 equivalent or nearly equivalent protons of four methyl groups (Figure 2; $g=2.0028 \pm 0.0001, \Delta B_{\mathrm{pp}}=$ $0.50 \mathrm{mT}$ ). The corresponding ${ }^{1} \mathrm{H}$-ENDOR spectrum (Figure 3, $v_{\mathrm{H}}=14.56 \mathrm{MHz}$ ) exhibited three pairs of signals which had an isotropic shape often encountered in matrices with protons of freely rotating methyl groups. Two such pairs at 5.3 and 34.4 $\mathrm{MHz}$ and at 4.7 and $33.8 \mathrm{MHz}\left(\left|a_{\mathrm{H}} / 2\right| \pm \nu_{\mathrm{H}}\right)$ match the hyperfine splitting of $1.4 \mathrm{mT}$ observed for 12 protons in the ESR spec-

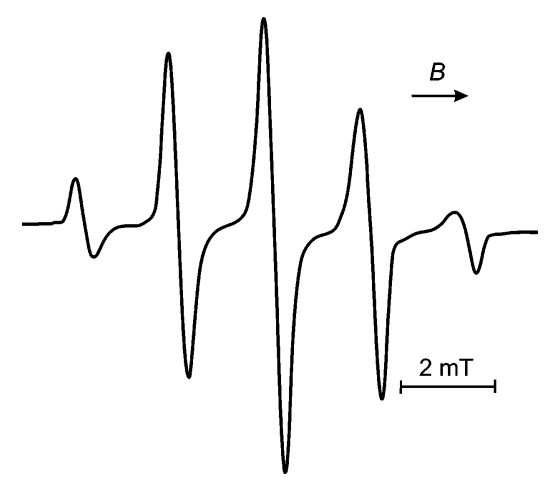

Figure 1. ESR spectrum of ionized dicyclopropylidenemethane (2) in a $\mathrm{CFCl}_{3}$ matrix at $150 \mathrm{~K}$.

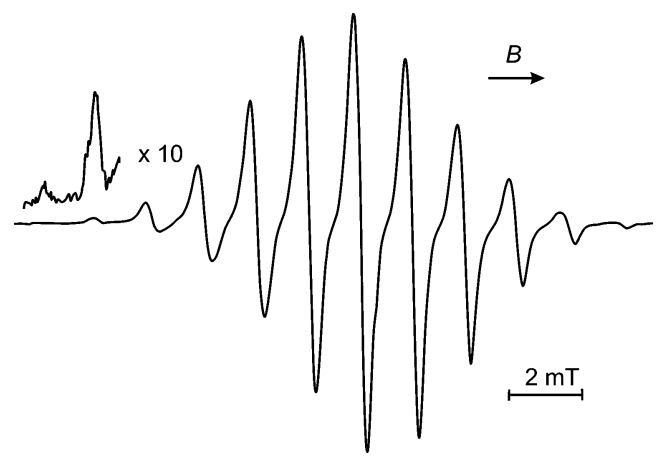

Figure 2. ESR spectrum of ionized octamethyldicyclopropylidenemethane $\left(2-\mathrm{Me}_{8}\right)$ in a $\mathrm{CFCl}_{3}$ matrix at $140 \mathrm{~K}$.

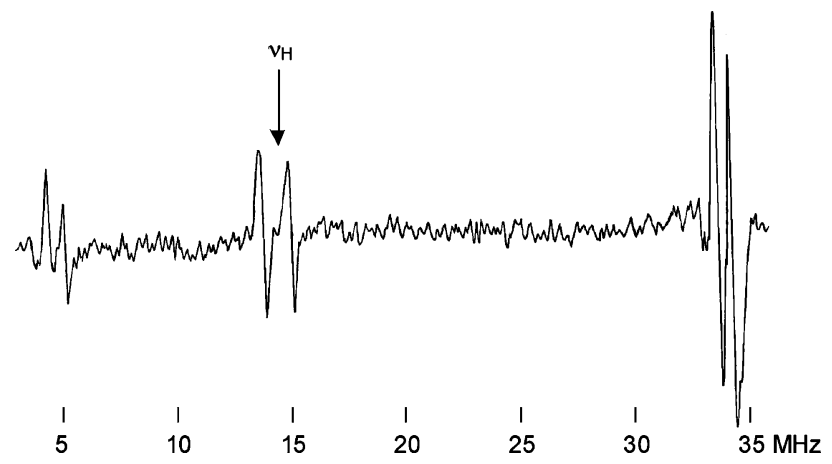

Figure 3. ${ }^{1} \mathrm{H}$-ENDOR spectrum of ionized octamethyldicyclopropylidenemethane $\left(2-\mathrm{Me}_{8}\right)$ in a $\mathrm{CFCl}_{3}$ matrix at $140 \mathrm{~K}$.

trum. They are associated with the coupling constants $\left|a_{\mathrm{H}}\right|=$ $39.7 \pm 0.3 \mathrm{MHz}$ or $1.42 \pm 0.01 \mathrm{mT}$ and $38.5 \pm 0.3 \mathrm{MHz}$ or $1.37 \pm 0.01 \mathrm{mT}$, each arising from six protons of two methyl substituents. In addition, a pair of signals at 13.94 and 15.18 $\mathrm{MHz}\left(v_{\mathrm{H}} \pm\left|a_{\mathrm{H}} / 2\right|\right)$ indicated a small $\left|a_{\mathrm{H}}\right|$ value of $1.24 \pm 0.01$ $\mathrm{MHz}$ or $0.044 \pm 0.003 \mathrm{mT}$ which must be due to the remaining 12 protons of four methyl groups.

As will be shown below, the ESR/ENDOR spectra observed upon ionization of parent $\mathbf{2}$ should be assigned to the primary radical cation, $\mathbf{2}^{\mathbf{}}$, whereas the analogous experimental evidence in the case of the ionized octamethyl derivative $2-\mathrm{Me}_{8}$ clearly indicates opening of one three-membered ring to yield the radical cation of 1-(1,1-dimethyl-3-isopropylallylidene)-2,2,3,3-tetramethylcyclopropane, $\mathbf{2 a}-\mathrm{Me}_{8}{ }^{\bullet+}$.

\section{Electronic and Vibrational Absorption Spectra}

Dicyclopropylidenemethane (2) was also subjected to ionization by $\mathrm{X}$ irradiation in Ar matrices, upon which a number of new bands appeared in the electronic and vibrational absorption spectra (Figures 4 and 5, red difference spectra). Upon subsequent bleaching at $>715 \mathrm{~nm}$, some of these new bands disappeared again, while others increased in intensity (Figures 4 and 5, blue difference spectra). An assignment of the features showing mirror-image relationships in the red and blue traces to the primary radical cation, $\mathbf{2}^{\mathbf{}}$, was attempted, but such an assignment turned out to be incompatible with DFT calculations for this species (see section 5). In particular, $\mathbf{2}^{\mathbf{+}}$ is predicted to have its strongest IR bands at ca. 740 and $1730 \mathrm{~cm}^{-1}$, i.e., in a region where almost no change was observed after ionization and subsequent bleaching. On the other hand, no vibrations are predicted for $\mathbf{2}^{\bullet+}$ in the region of $2000-2100 \mathrm{~cm}^{-1}$ where the experimental spectra show the strongest peaks. Moreover, TD-DFT calculations (cf. Section 5) predict no electronic absorptions (EA) above $570 \mathrm{~nm}$ for $\mathbf{2}^{\bullet+}$, whereas the species manifested experimentally is photosensitive to $>715 \mathrm{~nm}$ ir- 


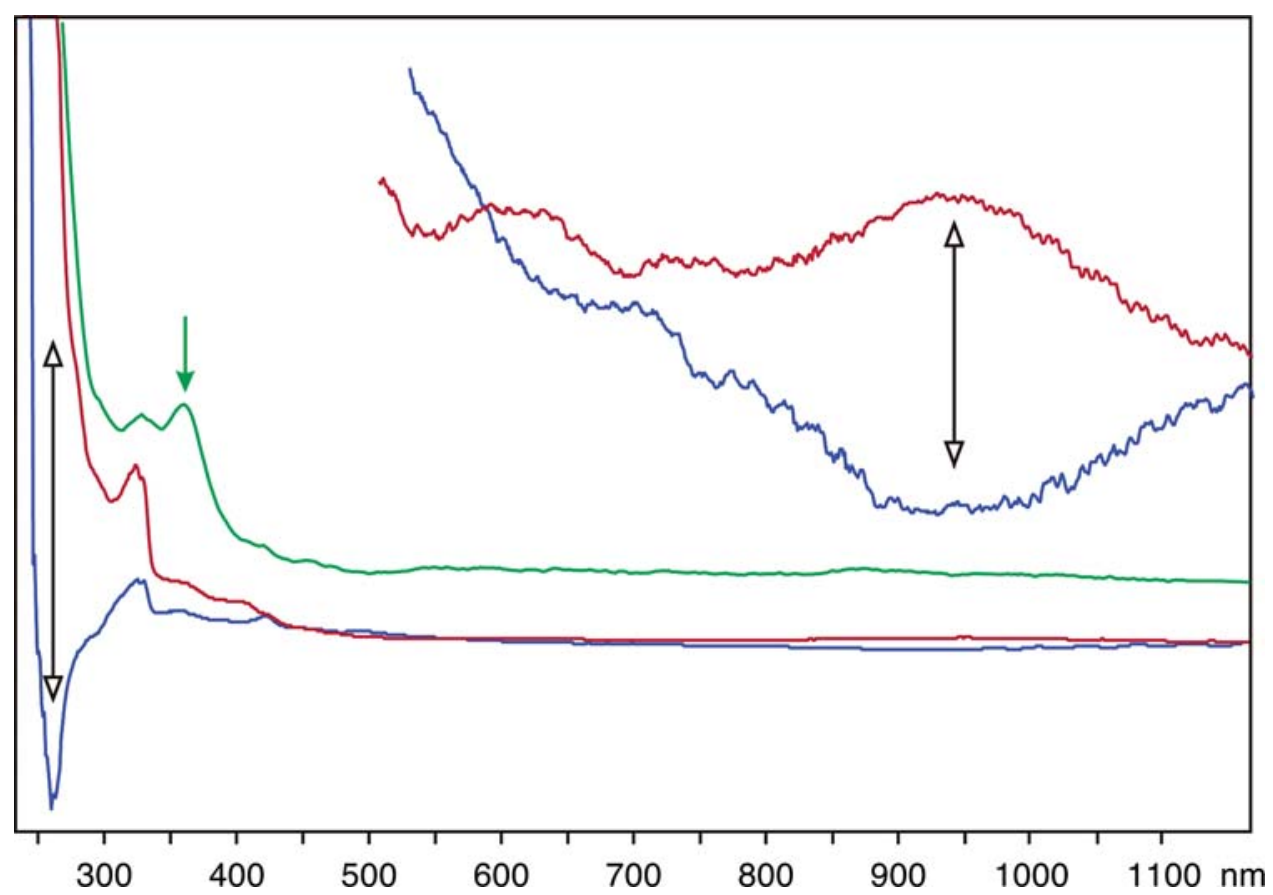

Figure 4. UV/vis difference spectra for the ionization of 2 in $\mathrm{Ar}$ at $10 \mathrm{~K}$ (red trace) and for subsequent bleaching at $>715 \mathrm{~nm}$ (blue trace). The green trace represents the difference spectrum for ionization of $\mathbf{2}$ in a Freon glass.

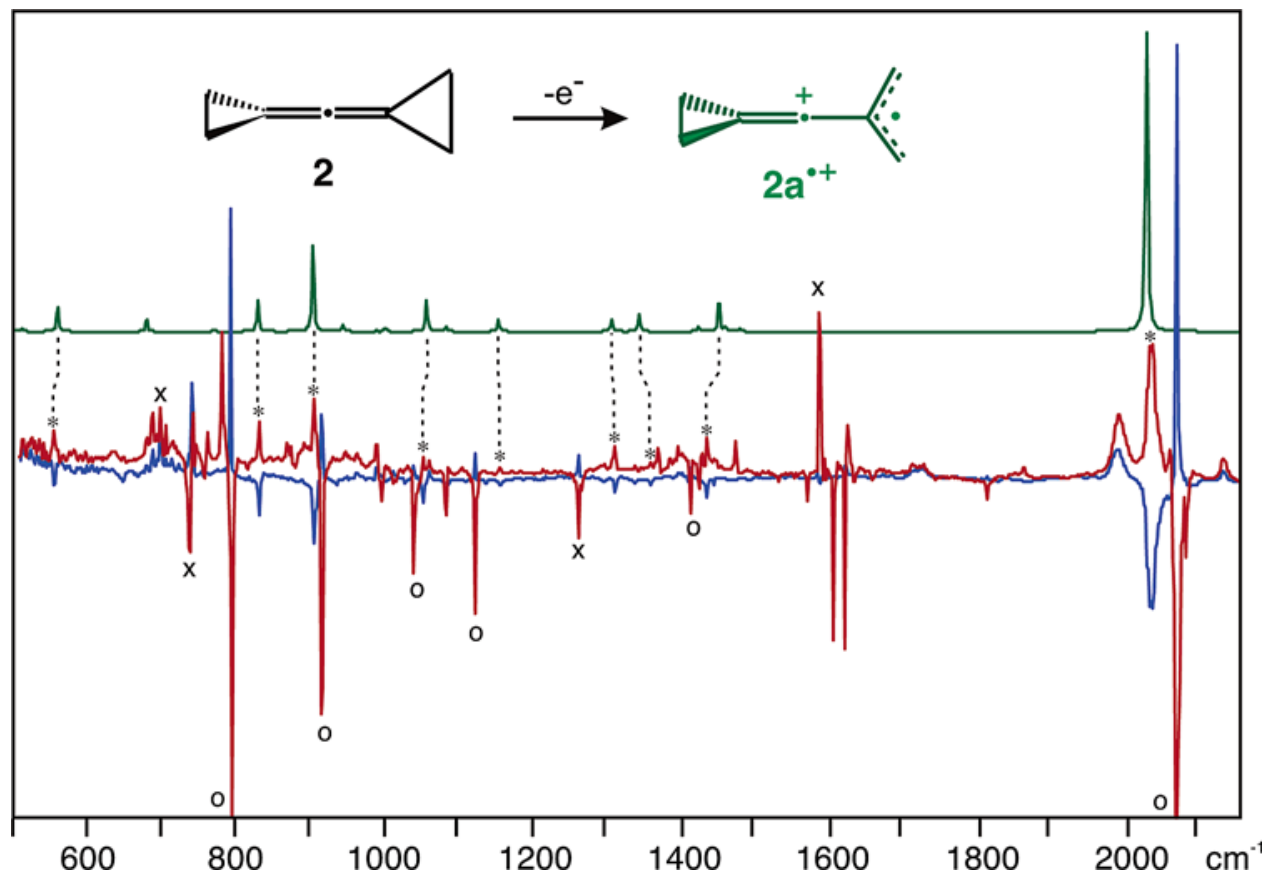

Figure 5. IR difference spectra for the ionization of $\mathbf{2}$ in Ar at $10 \mathrm{~K}$ (red trace) and for subsequent bleaching at $>715 \mathrm{~nm}$ (blue trace). Open circles indicate bands due to 2 , while the symbol $\mathrm{x}$ indicates bands associated with the added electron scavenger, $\mathrm{CH}_{2} \mathrm{Cl}_{2}$, and its radiolysis products.

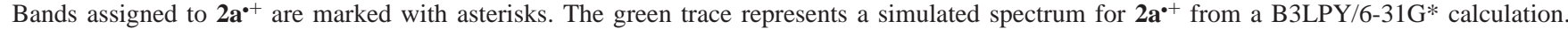

radiation and exhibits, in fact, a weak but distinct band peaking at ca. $940 \mathrm{~nm}$.

In contrast, the electronic and vibrational absorption spectra predicted for the radical cation of (2-methylallylidene)cyclopropane $\mathbf{2} \mathbf{a}^{\cdot+}$, are in excellent agreement with the observed ones: Not only should this radical cation, according to B3LYP calculations, have its strongest IR band at $2030 \mathrm{~cm}^{-1}$, but the remainder of the computed spectrum (green trace in Figure 5) also shows a pattern which is very similar to that of the IR peaks marked with asterisks; these peaks belong to the transient formed upon ionization and decaying on near-IR (NIR) bleaching. Furthermore, TD-DFT calculations predict a weak electronic absorption at $1019 \mathrm{~nm}(0.1 \mathrm{eV}$ below the observed NIR band $)$ but no other absorption of notable intensity down to $255 \mathrm{~nm}$. In this spectral region, three very close-lying transitions of a combined intensity about 40 times that of the NIR band are predicted to occur, in excellent accordance with the observed bands (cf. double arrows in Figure 4).

The above evidence leaves no doubt that the primary product of ionization of $\mathbf{2}$ in $\mathrm{Ar}$ matrices is (2-methylallylidene)cyclopropane $\mathbf{2}^{\bullet+}$; i.e., the parent cation $\mathbf{2}^{\bullet+}$ appears to undergo spontaneous ring opening upon ionization in $\mathrm{Ar}$, in contrast to the results of the above-described ESR/ENDOR experiments in freon glasses. Such differing behavior of metastable radical 


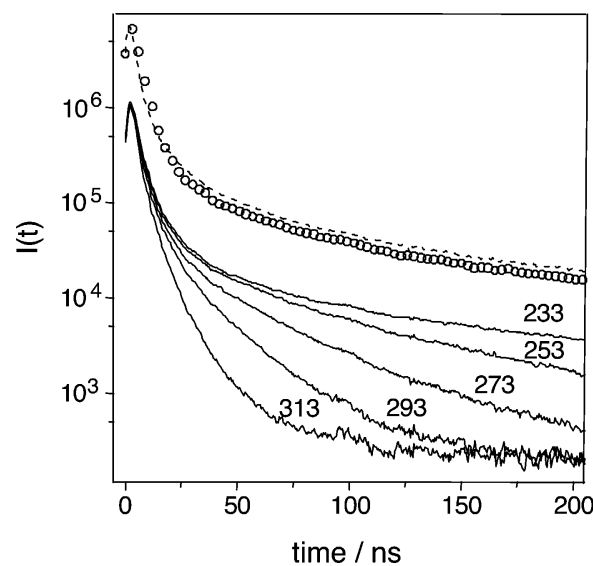

Figure 6. Experimental fluorescence decays of $0.01 \mathrm{M}$ solution of $2-\mathrm{Me}_{8}$ in $n$-octane $(+30 \mu \mathrm{M}$ of $p \mathrm{TP})$. Numbers in the plot refer to temperatures of the solutions. Circles and dashed line indicate the fluorescence decays for the $n$-octane solution of $30 \mu \mathrm{M}$ of $p \mathrm{TP}$ at 233 and $313 \mathrm{~K}$, respectively (shifted up for convenience).

cations in the two sets of experiments is not unusual. It is due to the fact that the incipient radical cations are imparted with much more excess energy if formed by charge transfer from $\mathrm{Ar}$ (gas-phase ionization energy $\mathrm{IE}=15.75 \mathrm{eV}$ ) than from freons (IE $=10-11 \mathrm{eV})$, and that they can dissipate this excess energy much more rapidly in the molecular solvent than in Ar, in which only lattice phonons are available to accept quanta of excess vibrational energy.

Indeed, when ionization was carried out by $\gamma$-irradiation in a freon glass that is suitable for optical studies $\left(\mathrm{CFCl}_{3} /\right.$ $\mathrm{CF}_{2} \mathrm{BrCF}_{2} \mathrm{Br} 1: 1$ ), the changes in the electronic absorption (EA) spectrum were quite different from those observed in $\mathrm{Ar}$ (green trace in Figure 4): The most evident new band now appeared at $360 \mathrm{~nm}$, in reasonable accord with the TD-B3LYP calculation which predicts the first intense band of $\mathbf{2}^{-+}$at $338 \mathrm{~nm}$. (The $335 \mathrm{~nm}$ band of a secondary product is also present in $\mathrm{Ar}$ matrices.) Unfortunately, it is impossible to record IR spectra in freons, so the assignment of the $360 \mathrm{~nm}$ band to $\mathbf{2}^{\cdot+}$ could not be substantiated by this method.

\section{Magnetic Field Effect on the Decay of the Recombination Fluorescence}

The rearrangement of $\mathbf{2}-\mathrm{Me}_{8}$ was also studied by following the decay of the delayed fluorescence from $0.01 \mathrm{M}$ solutions of $2-\mathrm{Me}_{8}$ in $n$-octane which also contained $30 \mathrm{mM} p$-terphenyl$d_{14}(p \mathrm{TP})$ as an electron acceptor and luminophore $\left(\tau_{\mathrm{fl}} \approx 1 \mathrm{~ns}\right)$ and which were exposed to X-ray pulses. Figure 6 shows such fluorescence decays recorded at $233-313 \mathrm{~K}$ and normalized in such a way that their maxima coincide, a procedure which amounts closely to a normalization with respect to the same absorbed dose. The top two curves in this Figure refer to the fluorescence decay of $30 \mathrm{mM} p \mathrm{TP}$ in $n$-octane (in the absence of $\left.2-\mathrm{Me}_{8}\right)$ at 233 and $313 \mathrm{~K}$.

Figure 7 (circles) illustrates the time-resolved magnetic field (TRMF) effect observed at $293 \mathrm{~K}$ for the above solution of $2-\mathrm{Me}_{8}$ as the ratio $I_{\mathrm{B}}(t) / I_{0}(t)$ of the fluorescence decay in a 0.1 $\mathrm{T}$ magnetic field $I_{\mathrm{B}}$ and in the absence of a magnetic field $\left(I_{0}\right) .{ }^{18-22}$ Similar results were also obtained at other temperatures. The effect of the external magnetic field proves that the fluorescence arises from the recombination of radical ion pairs.

The solid line in Figure 7 was obtained by modeling this TRMF effect within a semiclassical approximation, ${ }^{21-24}$ assuming that the ESR spectrum of the radical cation is unresolved with a peak-to-peak distance $\Delta B_{\mathrm{pp}}=0.62 \mathrm{mT}$ (taking the same parameters for $p \mathrm{TP}^{\bullet-}$ as in previous work ${ }^{20}$ ). The total

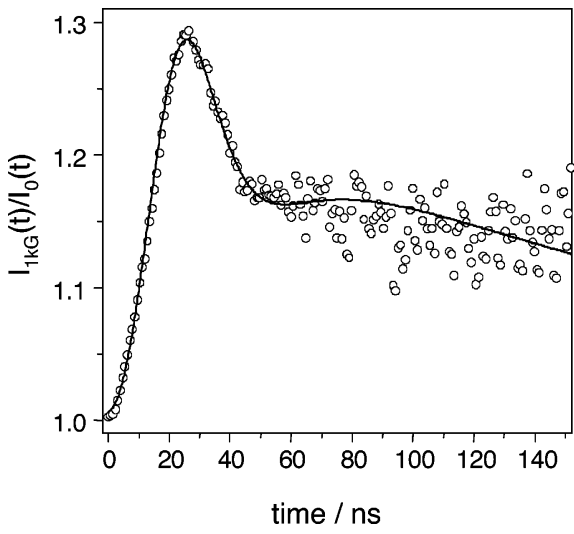

Figure 7. Ratio of the experimental fluorescence decay in a magnetic field of $0.1 \mathrm{~T}$ and in the absence of a field for $0.01 \mathrm{M}$ solution of $2-\mathrm{Me}_{8}$ and $30 \mu \mathrm{M}$ of $p \mathrm{TP}$ in $n$-octane at $293 \mathrm{~K}$ (circles). The solid line is the best fit of the effect, obtained under the assumption that the ESR spectra for both the radical cation $\left(\Delta B_{\mathrm{pp}}=0.62 \pm 0.03 \mathrm{mT}\right)$ and the radical anion $\left(\Delta B_{\mathrm{pp}}=0.14 \mathrm{mT}\right)$ are unresolved. Other parameters of the simulation are relaxation times $T_{2}=38 \pm 4 \mathrm{~ns}, T_{1}=250 \pm 50 \mathrm{~ns}$, and $\theta=0.28 \pm 0.01$ (see text for explanations).

width of the ESR spectrum is determined by the time at which $I_{\mathrm{B}}(t) / I_{0}(t)$ reaches a maximum, i.e., it is well-defined from the simulation. Other parameters for the simulation were the time constants for phase and spin-lattice relaxation, ${ }^{20,21}$ which can be considered as the inverse overall-relaxation rates for the radical pair involved, and the fraction $\theta$ of singlet spin-correlated radical pairs, which is determined by the probability of geminate recombination in the radiation track. The parameter $\theta$ governs the amplitude of the TRMF effect. ${ }^{25}$ The values of these simulation parameters are given in the caption to Figure 7. According to the simulation, the time constant of phase relaxation $\left(T_{2}\right)$ is independent of the magnetic field strength.

The simulation of the experimental TRMF curve, based on a model applicable to a radical cation with 12 or 24 equivalent protons, ${ }^{22}$ gave the same value of $\Delta B_{\mathrm{pp}}$. The manifestation of a possible hyperfine structure in the ESR spectrum is masked by a rather effective phase relaxation. The spin-lattice relaxation time $\left(T_{1}\right)$ determined from the simulation does not seem to be related to a real process but is more likely due to an additional channel of ${ }^{1} p \mathrm{TP}^{*}$ formation that is insensitive to the external magnetic field. As is evident from Figure 6, the resulting additional fluorescence amounts only to a few percent of the decay at $233 \mathrm{~K}$, but it becomes more important at elevated temperatures.

Whereas the decay of the fluorescence created by recombination of solvent radical cations with $p \mathrm{TP}^{\bullet-}$ (Figure 6) is only weakly sensitive to temperature (top two curves), addition of $2-\mathrm{Me}_{8}$ leads to a pronounced temperature dependence. At 298 $\mathrm{K}$, the primary octane radical cations are typically captured by unsaturated solutes with a rate constant of about $2 \times 10^{10} \mathrm{M}^{-1}$ $\mathrm{s}^{-1}$, which results in a mean time of ca. $5 \mathrm{~ns}$ for secondary radical cation formation. Assuming the rate constant to be inversely proportional to the viscosity of octane, this mean time increases to $15 \mathrm{~ns}$ at $233 \mathrm{~K}$. Subsequently, the fluorescence of ${ }^{1} p \mathrm{TP}^{*}$ arises predominantly from the recombination of $p \mathrm{TP}^{\bullet-}$ with the product(s) of the hole transfer from $n$-octane ${ }^{+}$to the solute, i.e., with $2-\mathrm{Me}_{8}{ }^{\circ}$, and the temperature dependence of the fluorescence decay is determined by properties of this radical cation, in particular the rate of its thermal decay (because of the short lifetime of ${ }^{1} p \mathrm{TP} *$, its quenching by $2-\mathrm{Me}_{8}$ can be excluded from consideration).

To estimate the activation energy of the process which transforms $2-\mathrm{Me}_{8}{ }^{\circ+}$ into a product which does not give rise to 


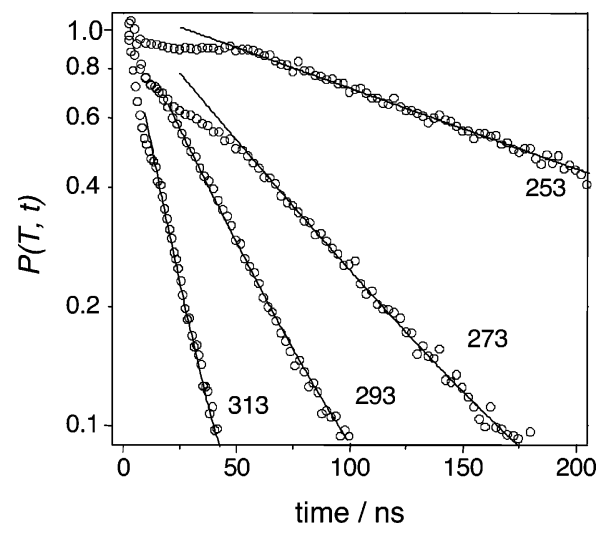

Figure 8. Ratios $I(T, t) / I(233, t)$ of experimental decays from Figure 6 to the decay observed at $233 \mathrm{~K}$ (circles). Numbers in the plot indicate temperatures. Straight lines are the best fit by an exponential function of the long-time tail of the experimental curves.

${ }^{1} p \mathrm{TP}^{*}$ upon recombination with $p \mathrm{TP}^{\bullet-}$, we have used an approach similar to that described previously. ${ }^{26}$ The decay of the fluorescence intensity, $I(T, t)$, depends on the diffusioncontrolled ion pair recombination rate, $F(t, T)$, and, in the present case, on the probability $P(T, t)$ that $2-\mathrm{Me}_{8}{ }^{\circ}{ }^{+}$is transformed into another species. The two upper curves in Figure 6 show that, in the absence of $\mathbf{2}-\mathrm{Me}_{8}$, the decay of the fluorescence intensity is rather independent of temperature, at least at times above $30-50 \mathrm{~ns}$, so it was assumed that $P(T, t)$ alone determines the temperature dependence of $I(T, t)$.

$$
I(T, t) \sim F(t) P(T, t)
$$

As the fluorescence decay for $\mathbf{2}-\mathrm{Me}_{8}$ solutions at $233 \mathrm{~K}$ is very similar to that obtained in the absence of the solute, it is reasonable to conclude that $P(233, t) \approx 1$ in the time domain studied. Thus, the lifetime distribution of $2-\mathrm{Me}_{8}{ }^{+}$is given by

$$
P(T, t) \approx I(T, t) / I(233, t)
$$

In Figure 8, the ratios of curves obtained at $313-253 \mathrm{~K}$ to that for $233 \mathrm{~K}$ in Figure 6 are presented on a semilogarithmic scale. Thereby, it is found that the time dependence of $P(T)$ is close to exponential, except for the first $30-50 \mathrm{~ns}$ where the fluorescence decay rate depends on the temperature. Presumably, besides the ion pair recombination rate $F(t)$, it is the lifetime of the solvent excited states, which transfer their energy to $p \mathrm{TP}$, that is affected in this time domain. At longer times, very similar curves were obtained when $I(233, t)$ is replaced in the denominator of (2) by the fluorescence decays registered at the corresponding temperature $T$ in the absence of $\mathbf{2}-\mathrm{Me}_{8}$.

It is important to emphasize that the $P(T, t)$ curves do not depend significantly on the concentration of $2-\mathrm{Me}_{8}$. Assuming that the process transforming $2-\mathrm{Me}_{8}{ }^{\circ}$ is unimolecular, one can obtain corresponding rate constants $k$. The results of such an evaluation are presented in Figure 9 as a semilogarithmic Arrhenius plot from which $A=1.9 \pm 1.0 \times 10^{13} \mathrm{~s}^{-1}$ and $E_{\mathrm{a}}=$ $32.6 \pm 6.3 \mathrm{~kJ} \cdot \mathrm{mol}^{-1}$ are derived by linear regression.

What remains to be explained is why $p \mathrm{TP}^{\bullet-}$ yields ${ }^{1} p \mathrm{TP}^{*}$ on recombination with $2-\mathrm{Me}_{8}{ }^{\circ+}$ but not with $2 \mathbf{a}-\mathrm{Me}_{8}{ }^{\bullet+}$. Recombination fluorescence can only occur if the sum of the energy gained on reduction of the radical cation minus that required to oxidize the radical anion exceeds the excitation energy of one of the two resulting neutral compounds ${ }^{27}$ (that of $p$ TP being ca. $4 \mathrm{eV}$ ). Because the neutral ground state of reduced $2 \mathbf{a}-\mathrm{Me}_{8}{ }^{+}$corresponds to a diradicaloid species, its oxidation potential is expected to be much lower than that of its precursor, $2-\mathrm{Me}_{8}$ (a

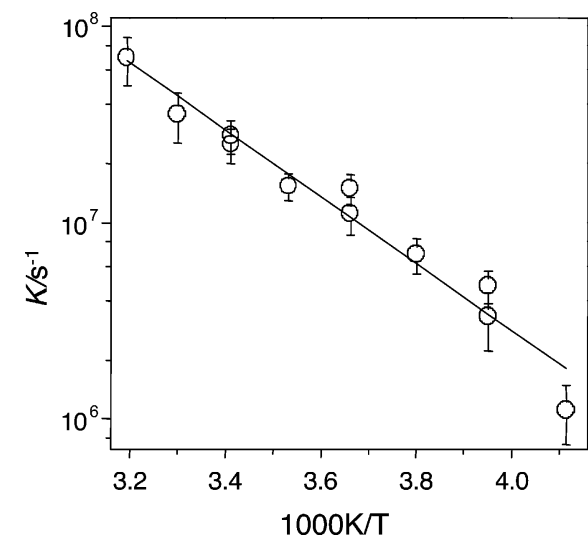

Figure 9. Arrhenius plot for the rate constants of radical-cation transformation. The solid line is the best fit with $A=(1.9 \pm 1.0) \cdot 10^{13}$ $\mathrm{s}^{-1}$ and $E_{\mathrm{a}}=(32.6 \pm 6.3) \mathrm{kJ} \cdot \mathrm{mol}^{-1}$.

normal, closed-shell species), so that the energy gained on reduction of $2 \mathbf{a}-\mathrm{Me}_{8}{ }^{\circ+}$ would not be sufficient to excite $p$ TP. In fact, it is only by virtue of this failure of $2 \mathbf{a}-\mathrm{Me}_{8}{ }^{\bullet+}$ to generate recombination fluorescence with $p \mathrm{TP}^{--}$that the kinetics for the decay of $2-\mathrm{Me}_{8}{ }^{+}$could be observed.

\section{Calculations and Discussion}

The neutral allenes $\mathbf{2}$ and $\mathbf{2}-\mathrm{Me}_{8}$ have $D_{2 d}$ symmetry and a degenerate HOMO, hence the resulting radical cations are subject to Jahn-Teller distortion. This distortion results in the loss of the $S_{4}$ axis and in equilibrium structures of $D_{2}$ symmetry, i.e., the eight hydrogen atoms or methyl groups form two groups of four equivalent ones with very different hyperfine-coupling constants. These equilbrium structures can interconvert via two transition states: in one of them the carbon atoms of the dicyclopropylidenemethane skeleton are coplanar $\left(D_{2 h}\right)$, whereas in the other they are perpendicular (see Scheme 3). However, this latter transition state cannot have $D_{2 d}$ symmetry (because such structures represent conical intersections) but is distorted to $C_{2 v}$ by making the two halves of the molecule unequal. In $2-\mathrm{Me}_{8}{ }^{++}$, second order vibronic interaction effects lead to a further distortion of this transition state (a bending of one of the cyclopropylidene moieties), so that the "perpendicular" transition state finally has only a plane of symmetry left $\left(C_{s}\right)$.

\section{SCHEME 3}

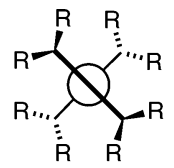

$D_{2 d}$

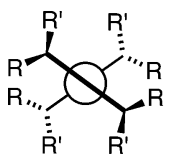

$D_{2}$

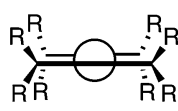

$D_{2 h}$

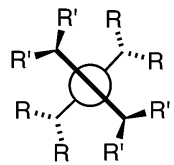

$C_{2 v}$
Table 1 lists the relative B3LYP/6-31G* energies of $\mathbf{2}^{\bullet+}$ and $2-\mathrm{Me}_{8}{ }^{\bullet+}$, the transition states for internal rotation and for ring

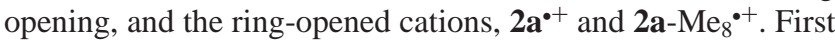
we note that the barriers for internal rotation in $2^{\circ+}$ are too high to make the eight hydrogen atoms equivalent at $150 \mathrm{~K}$ on the hyperfine time scale, whereas the same barriers in $2-\mathrm{Me}_{8}{ }^{\circ}$ are low enough to lead to rapid equilibration at room temperature, 
TABLE 1: Relative Energies of the Radical Cations Discussed in the Present Study

\begin{tabular}{|c|c|c|}
\hline species & symmetry & $H_{\mathrm{rel}}{ }^{a}\left(\mathrm{~kJ} \cdot \mathrm{mol}^{-1}\right)$ \\
\hline $2^{++}+4$ & $D_{2}$ & $(0)^{b}$ \\
\hline TS1 (internal rotation in $\mathbf{2}^{{ }^{+}}$) & $D_{2 h}$ & 25.0 \\
\hline TS2 (internal rotation in $\mathbf{2}^{\cdot+}$ ) & $C_{2 v}$ & 26.7 \\
\hline $\operatorname{TS}\left(\mathbf{2}^{+} \rightarrow \mathbf{2}^{\mathbf{a}^{+}}\right)$ & $C_{1}$ & 77.8 \\
\hline $2 \mathbf{a}^{++}$ & $C_{2 v}$ & -16.1 \\
\hline $\operatorname{TS}\left(\mathbf{2 a}^{\mathbf{a}^{+}} \rightarrow \mathbf{3}^{\mathbf{}^{+}}\right)$ & $C_{1}$ & 204.8 \\
\hline $3^{+}+a^{+a}$ & $C_{1}$ & -1.2 \\
\hline $2-\mathrm{Me}_{8}{ }^{++}$ & $D_{2}$ & $(0)^{b}$ \\
\hline TS1 (internal rotation in $2-\mathrm{Me}_{8}{ }^{+}$) & $D_{2 h}$ & 16.1 \\
\hline TS2 (internal rotation in $\mathbf{2}-\mathrm{Me}_{8}{ }^{+}$) & $C_{s}$ & 19.7 \\
\hline $\operatorname{TS}\left(\mathbf{2}-\mathrm{Me}_{8}{ }^{\bullet+} \rightarrow \mathbf{2 a}-\mathrm{Me}_{8}{ }^{\bullet+}\right)$ & $C_{1}$ & 35.8 \\
\hline $2 a-\mathrm{Me}_{8}{ }^{++}$ & $C_{2}$ & -53.1 \\
\hline $\operatorname{TS}\left(2-\mathrm{Me}_{8}{ }^{\bullet+} \rightarrow 3-\mathrm{Me}_{8}{ }^{\cdot+}\right)$ & $C_{1}$ & $(\text { ca. } 150)^{c}$ \\
\hline $3-\mathrm{Me}_{8}{ }^{+}$ & $C_{1}$ & -53.7 \\
\hline
\end{tabular}

${ }^{a}$ Relative enthalpies in $\mathrm{kJ} \cdot \mathrm{mol}^{-1}$ from B3LYP/6-31G* calculations. ${ }^{b}$ Total energies and thermal corrections are listed in the Supporting Information. ${ }^{c}$ Transition state not located; Activation enthalpy estimated from reaction scan.

in accord with the assumptions made in the modeling of the magnetic field effect on the recombination fluorescence.

Opening of one ring in ionized dicyclopropylidenemethane $\left(2^{+}\right)$is exothermic by ca. $16 \mathrm{~kJ} \cdot \mathrm{mol}^{-1}$ but requires an activation energy of almost $78 \mathrm{~kJ} \cdot \mathrm{mol}^{-1}$. This value is considerably higher than the corresponding barrier $\left(33 \mathrm{~kJ} \cdot \mathrm{mol}^{-1}\right)$ for the opening of one ring in ionized bicyclopropylidene $\left(\mathbf{1}^{\bullet+}\right)$, which led to a transient species that rapidly rearranged by opening of the second ring to the radical cation of tetramethyleneethane $\left(\mathbf{1 b}^{\mathbf{}+}\right) .{ }^{11}$ On the other hand, this barrier is close to the activation energy for ring opening of the cyclopropyl radical to the allyl radical $\left(92 \pm 8 \mathrm{~kJ} \cdot \mathrm{mol}^{-1}\right),{ }^{28-30}$ which in this case corresponds to the interconversion of $\mathbf{2}^{\mathbf{+}}$ to $\mathbf{2 a}^{\mathbf{}^{+}}$. Admittedly, formation of the resonance form of $\mathbf{2 a}^{\bullet+}$ which bears the charge in the allylic moiety (see $\mathbf{2} \mathbf{a}^{\mathbf{\prime}+}$ in Scheme 2) appears to be preferable, as the ring opening of the cyclopropyl to the allyl cation is nearly activationless. ${ }^{30}$ However, the calculations show that in the ground state of $2 \mathbf{a}^{\mathbf{}+}$ the spin resides mostly in the allyl moiety, the resonance form $\mathbf{2}^{\mathbf{\prime}+}$ representing an excited state of $\mathbf{2}^{\mathbf{}^{+}}$ (see below).

For ionized octamethyldicyclopropylidenemethane $\left(2-\mathrm{Me}_{8}{ }^{\bullet+}\right)$, opening of one ring is predicted by these calculations to be exothermic by as much as $53 \mathrm{~kJ} \cdot \mathrm{mol}^{-1}$ and to involve a barrier of only $36 \mathrm{~kJ} \cdot \mathrm{mol}^{-1}$. This value compares well with the activation energy for the decay of $2-\mathrm{Me}_{8}{ }^{\bullet+}\left(32.6 \pm 6.3 \mathrm{~kJ} \cdot \mathrm{mol}^{-1}\right)$ that was estimated from the kinetics of the recombinationfluorescence decay (cf. previous section). The small activation entropy that is calculated for the ring opening of $2-\mathrm{Me}_{8}{ }^{\bullet+}(22.6$ $\left.\mathrm{J} \cdot \mathrm{K}^{-1} \mathrm{~mol}^{-1}\right)$ is also compatible with the $A$ factor $\left(2 \times 10^{13}\right.$ $\mathrm{s}^{-1}$ ) that resulted from the same measurements. This supports the notion that it is indeed the ring-opening process which is responsible for the inhibition of the recombination fluorescence.

In contrast to the case of $\mathbf{1 a}^{\bullet+}$, opening of the second ring in ionized $\mathbf{2 a}^{\bullet+}$ involves a very high barrier $\left(\Delta H^{\ddagger}=204 \mathrm{~kJ} \cdot \mathrm{mol}^{-1}\right)$ and does not lead to the expected tetramethyleneallene radical cation (which turns out to have a quartet ground state and lies $165 \mathrm{~kJ} \cdot \mathrm{mol}^{-1}$ above $2 \mathbf{a}^{\bullet+}$ ) but collapses instead to the bisallylic cation $\mathbf{3}^{\mathbf{}}$ which has nearly the same energy as $\mathbf{2}^{\mathbf{a}^{+}}$(Scheme 4). For the octamethyl derivative it proved impossible to locate

\section{SCHEME 4}

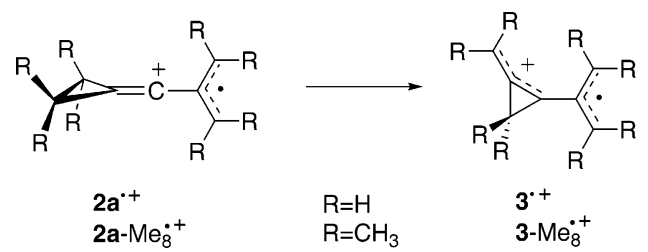

the transition state for opening the second ring (from a scan of the potential-energy surface along the reaction coordinate the activation enthalpy was estimated to be about $150 \mathrm{~kJ} \cdot \mathrm{mol}^{-1}$ ), but the resulting $3-\mathrm{Me}_{8}{ }^{\circ+}$ is almost $54 \mathrm{~kJ} \cdot \mathrm{mol}^{-1}$ more stable than $2-\mathrm{Me}_{8}{ }^{\bullet+}$ and has almost the same energy as $\mathbf{2 a}-\mathrm{Me}_{8}{ }^{\bullet+}$. From the above results and because no spectra were observed that are compatible with $3^{\bullet+}$ and $3-\mathrm{Me}_{8}{ }^{\bullet+}$, respectively, we conclude that opening of the second ring does not occur.

Therefore, only those radical cations, $2 \mathbf{a}^{\bullet+}$ and $\mathbf{2} \mathbf{a}-\mathbf{M e}_{8}{ }^{\bullet+}$, in which a single cyclopropropylidene moiety is opened to an allyl $\pi$-system, should be considered as viable secondary products of the primary radical cations, $\mathbf{2}^{\bullet+}$ and $2-\mathrm{Me}_{8}{ }^{\boldsymbol{}}$, respectively. Also, no rearrangement of $\mathbf{2}^{\cdot+}$ and $2-\mathrm{Me}_{8}{ }^{\bullet+}$ of the type corresponding to the well-known ring opening of cyclopropylcarbinyl to homoallyl cations ${ }^{31,32}$ or to the ring-enlarging rearrangement of cyclopropylmethyl to cyclobutyl cations ${ }^{33}$ was observed.

Table 2 gives the excitation wavelengths and transition moments predicted for the dipole-allowed transitions in $\mathbf{2}^{\mathbf{}}+$ and $\mathbf{2 a}^{\mathbf{}^{+}}$by the TD-B3LYP method. These calculations show clearly that $\mathbf{2}^{\bullet+}$ has no NIR absorptions, and that the first palpable band of this species should occur in the UV. With regard to $\mathbf{2}^{\bullet+}$, the NIR transition (experimental $\lambda_{\max }=950 \mathrm{~nm}$ ) should correspond to rather pure HOMO $\rightarrow$ LUMO excitation, while the transitions around $250 \mathrm{~nm}$ that give rise to the intense UV band are due to transitions into highly mixed excited states.

The shape of the HOMO depicted in Figure 10 indicates that the spin in $\mathbf{2} \mathbf{a}^{\mathbf{}}+$ is essentially accommodated in the allylic moiety, whereas the LUMO (which can be thought of formally bearing the positive charge) is located mainly on the central carbon atom of the allene $\pi$-system. Thus, $\mathbf{2} \mathbf{a}^{\bullet+}$ can be regarded as a distonic radical cation, ${ }^{34}$ and the resonance structure $\mathbf{2} \mathbf{a}^{\mathbf{\bullet}+}$ corresponds to the HOMO $\rightarrow$ LUMO excited state of $\mathbf{2} \mathbf{a}^{\bullet+}$.

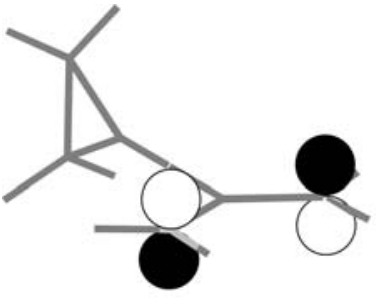

HOMO

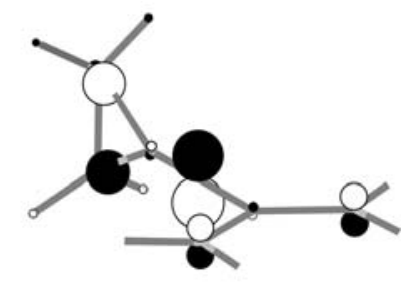

$2 \mathrm{a}^{*+}$
LUMO
Figure 10. Frontier MOs of the radical cation of (cyclopropylidene-

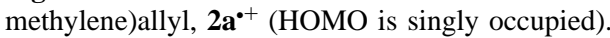

Table 3 lists coupling constants $a_{\mathrm{H}}$ computed by the B3LYP/ 6-31G* method for the primary radical cations $\mathbf{2}^{\bullet+}$ and $2-\mathrm{Me}_{8}{ }^{\bullet+}$,

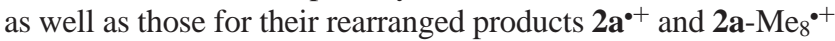
with one ring-opened cyclopropylidene moiety. These values are presented along with the hyperfine data observed by ESR and ENDOR spectroscopy upon ionization of $\mathbf{2}$ and $\mathbf{2}-\mathrm{Me}_{8}$ in

TABLE 2: Dipole-Allowed Transitions of $2^{\cdot+}$ and $2 a^{{ }^{+}}$from TD/B3LYP Calculations ${ }^{a}$

$\begin{array}{llllll}\mathbf{2}^{\bullet+} & 572(0.0014) & 338(0.0269) & 323(0.0005) & 300(0.0019) & 293(0.0101) \\ \mathbf{2}^{\cdot++} & 1019(0.0104) & 330(\approx 0) & 269(\approx 0) & 255(0.0029) & 255(0.1526)\end{array}$

${ }^{a}$ Wavelengths in $\mathrm{nm}$; oscillator strength in parentheses (arbitrary relative units). 
TABLE 3: Calculated and Experimental Coupling Constants, in $\mathbf{m T}$, for the Allyl Radical and the Radical Cations $1^{\bullet+}, 2^{\bullet+}$, $2-\mathrm{Me}_{8}{ }^{+}, \mathbf{2 a}^{\cdot+}$, and $2 \mathrm{a}-\mathrm{Me}_{8}{ }^{+}$

\begin{tabular}{|c|c|c|c|}
\hline & symmetry & $a_{\mathrm{H}}$ calculated & $\left|a_{\mathrm{H}}\right|$ experimental \\
\hline allyl radical & $C_{2 v}$ & $-1.65\left(2 \mathrm{H}_{\text {exo }}\right) ;-1.58\left(2 \mathrm{H}_{\text {endo }}\right) ;+0.50(2 \mathrm{H})$ & $1.43(2 \mathrm{H}) ; 1.38(2 \mathrm{H}) ; 0.42(2 \mathrm{H})$ \\
\hline $1^{+}+$ & $D_{2}$ & $+2.44(4 \mathrm{H}) ;-0.27(4 \mathrm{H})$ & $2.21(4 \mathrm{H}) ; 0.27(4 \mathrm{H})$ \\
\hline $2^{+}+$ & $D_{2}$ & $+2.00(4 \mathrm{H}) ;+0.09(4 \mathrm{H})$ & $1.96(4 \mathrm{H}) ; 0.125(4 \mathrm{H})$ \\
\hline $2 \mathbf{a}^{++}$ & $C_{2 v}$ & $-1.75\left(2 \mathrm{H}_{\mathrm{exo}}\right) ;-1.68\left(2 \mathrm{H}_{\mathrm{endo}}\right) ;-0.052(4 \mathrm{H})$ & not observed by ESR \\
\hline $2-\mathrm{Me}_{8} \cdot+$ & $D_{2}$ & $+0.32(12 \mathrm{H}) ;-0.02(12 \mathrm{H})$ & not observed by ESR \\
\hline $2 \mathrm{a}-\mathrm{Me}_{8}{ }^{+}$ & $C_{2}$ & $+1.46\left(6 \mathrm{H}_{\text {exo }}\right) ;+1.04\left(6 \mathrm{H}_{\text {endo }}\right) ;-0.060(6 \mathrm{H}) ;-0.045(6 \mathrm{H})$ & $1.42(6 \mathrm{H}) ; 1.30(6 \mathrm{H}) ; 0.044(12 \mathrm{H})$ \\
\hline
\end{tabular}

$\mathrm{CFCl}_{3}$ matrices. The calculated and experimental coupling constants for the allyl radical $^{35}$ and $\mathbf{1}^{\bullet+10}$ are also given for comparison.

In the case of the ionized parent $\mathbf{2}$, the computed values agree much better with the experimental data for the primary radical cation $\mathbf{2}^{\mathbf{}+}$ than with those of the rearranged species $\mathbf{2 a}^{\mathbf{}}+$ having one allylic moiety (the two major $\left|a_{\mathrm{H}}\right|$ values calculated by

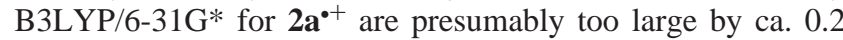
$\mathrm{mT}$, as are those for the protons in the 1,3-positions of the allyl radical ${ }^{36}$ ). Like in $\mathbf{1}^{\mathbf{}}$, the two protons in a methylene group of $\mathbf{2}^{\mathbf{}+}$ are nonequivalent, thus causing the eight protons to split into two sets of four. This splitting is due to the fact that $\mathbf{2}$ has a degenerate HOMO from which an electron is removed, and, therefore, the radical cation is subject to Jahn-Teller distortion which reduces its symmetry from $D_{2 d}$ to $D_{2}$ (in $\mathbf{1}^{\mathbf{}+}$, the symmetry is also reduced, from $D_{2 h}$ in $\mathbf{1}$ to $D_{2}$, but there the distortion is not due to a degeneracy of states in vertically formed $\mathbf{1}^{\bullet+}$, but to vibronic coupling of the ground state with a lowlying excited state, as in other olefins ${ }^{37}$ ).

Assuming that the two $D_{2}$ equilibrium structures of $2-\mathrm{Me}_{8}{ }^{\bullet+}$ interconvert rapidly at room temperature (i.e., all 24 protons become equivalent) on a ns time scale, one predicts $a_{\mathrm{H}}=$ $(1 / 2)(+0.32-0.02) \mathrm{m} T=+0.15 \mathrm{mT}$ and $\Delta B_{\mathrm{pp}}=0.15 \mathrm{mT} \sqrt{24}$ $=0.73 \mathrm{mT}$, in good accord with the estimate of $\Delta B_{\mathrm{pp}}=0.62$ $\mathrm{mT}$ from the TRMF measurements presented in the previous section. This result lends support to the notion that the species which causes fluorescence on recombination with $p \mathrm{TP}^{{ }^{-}-}$in $n$-octane is indeed $2-\mathrm{Me}_{8}{ }^{\bullet+}$. On the other hand, comparison between the observed ESR and ENDOR spectra with the predictions clearly indicates that these spectra arise from the allylic radical cation $\mathbf{2 a}-\mathrm{Me}_{8}{ }^{\bullet+}$ having one opened ring.

The two major coupling constants $\left|a_{\mathrm{H}}\right|$ of 1.42 and $1.37 \mathrm{mT}$, each for a set of six protons, which are assigned to the exoand endo-positioned methyl groups, respectively, in the allylic moiety of $\mathbf{2 a}-\mathrm{Me}_{8}{ }^{+}$, are equal or very close to the corresponding values of 1.42 and $1.30 \mathrm{mT}$ reported for the 1,1,3,3-tetramethylallyl radical. ${ }^{38}$ The calculations indicate a deviation of $\mathbf{2 a}-\mathrm{Me}_{8}{ }^{\bullet+}$ from $C_{2 v}$ symmetry, due to steric congestion by the endo-methyl substituents. At the energy minimum, this deviation lowers the symmetry to $C_{2}$ by decreasing the dihedral angle between the allyl and the cyclopropylidenemethyl moieties from 90 to $79^{\circ}$. It also splits the set of 12 protons in the four methyl groups at the unrearranged ring into two sets of six. However, the small difference in their coupling constants $\left|a_{\mathrm{H}}\right|$, which is predicted as $0.015 \mathrm{mT}$ or $0.4 \mathrm{MHz}$ (and might actually be even less), does not show up in the ENDOR spectrum of $\mathbf{2} \mathbf{a}-\mathrm{Me}_{8}{ }^{\bullet+}$.

It is informative to compare the structure of this radical cation with that of $\mathbf{1 b}-\mathrm{Me}_{8}{ }^{++}$, the bisallylic radical cation of octamethyltetramethyleneethane formed upon ionization of octamethylbicyclopropylidene $\left(\mathbf{1}-\mathrm{Me}_{8}{ }^{\bullet+}\right) .{ }^{11}$ The two structures have some common features with respect to the spin distribution. However, in $\mathbf{2} \mathbf{a}-\mathrm{Me}_{8}{ }^{\mathbf{}}$, the spin is exclusively accommodated in a single allylic moiety which is nearly perpendicular to the unrearranged cyclopropylidenemethylidene moiety, so that the two major coupling constants $\left|a_{\mathrm{H}}\right|$ of ca. $1.4 \mathrm{mT}$ are virtually those for the 1,1,3,3-tetramethylallyl radical. In contrast, the spin appears to be largely but not fully localized in one of the two equivalent allylic moieties (dihedral angle $30-40^{\circ}$ ) of 1b- $\mathrm{Me}_{8}{ }^{+}$, because such coupling constants are reduced to ca. $1.1 \mathrm{mT}^{11}$

\section{Conclusions}

Dicyclopropylidenemethane (2) and its octamethyl derivative $\left(2-\mathrm{Me}_{8}\right)$ were subjected to ionization by $\gamma$-irradiation of frozen freon solutions and the former was also subject to ionization by $\mathrm{X}$ irradiation in $\mathrm{Ar}$ matrices. ESR/ENDOR and UV/vis spectra of ionized $\mathbf{2}$ indicate that in the freons the structure of the neutral precursor is essentially retained up to $150 \mathrm{~K}$, yielding the Jahn-Teller distorted primary radical cation, $\mathbf{2}^{\bullet+}$, whereas in $\mathrm{Ar}$, in which more excess energy is imparted onto the incipient radical cations, only the ring-opening product, the radical cation of (2-methylallylidene)cyclopropane $\mathbf{2 \mathbf { a } ^ { \mathbf { } }}$, can be observed (and fully characterized by UV-vis-NIR and IR spectroscopies). In contrast to the previously investigated case of the radical cation of bicyclopropylidene (1), in which opening of the second three-membered ring occurs spontaneously, this process is highly unfavorable in $\mathbf{2} \mathbf{a}^{\mathbf{}+}$, because it would result in a species with three unpaired electrons and a quartet ground state.

Like the octamethyl derivative of $\mathbf{1}$, that of $\mathbf{2}$ is more prone to oxidative ring opening than the unsubstituted compound. Accordingly, the primary radical cation, $2-\mathrm{Me}_{8}{ }^{\circ}$, cannot be observed even in freon matrices at $77 \mathrm{~K}$. The larger hyperfinecoupling constants $\left|a_{\mathrm{H}}\right|$ in the ESR/ENDOR spectra recorded after ionization of $\mathbf{2}-\mathrm{Me}_{8}$ are almost identical to the corresponding values for the 1,1,3,3-tetramethylallyl radical, which leaves no doubt about the assignment of these spectra to $\mathbf{2 a}-\mathrm{Me}_{8}{ }^{\bullet+}$ where one of the cyclopropylidene moieties has undergone ring opening. By virtue of the fact that on recombination of the radical anion of $p$-terphenyl with $2-\mathrm{Me}_{8}{ }^{\bullet+}$, excited $p$-terphenyl is generated, but not on recombination with $\mathbf{2 a -} \mathrm{Me}_{8}{ }^{+}$, we were able to detect $2-\mathrm{Me}_{8}{ }^{\circ+}$ by the magnetic field effect on the decay of the recombination fluorescence in $n$-octane and to determine the kinetics of the ring-opening process of $2-\mathrm{Me}_{8}{ }^{\bullet+}$ by monitoring the temperature dependence of this decay. As in $\mathbf{2} \mathbf{a}^{\mathbf{}}$, opening of the second cyclopropylidene ring in $\mathbf{2 a -} \mathbf{M e}_{8}{ }^{+}$is highly unfavorable.

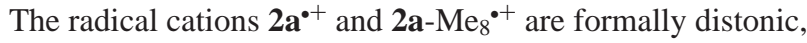
with the unpaired electron residing in the allylic moiety and the positive charge on the central $\mathrm{C}$ atom. The intact threemembered ring assumes a "bisected" conformation" ${ }^{1,39}$ with regard to the allene $\pi$-system, thus favoring optimal interaction of the antisymmetric Walsh MO with the $\pi$-MOs and hence efficient stabilization of the positive charge.

\section{Methods}

Synthesis. The allenes $\mathbf{2}^{17}$ and $\mathbf{2}-\mathrm{Me}_{8}{ }^{16}$ were synthesized according to previously published procedures.

Freon Glass Experiments. Ca. $10^{-2} \mathrm{M}$ solutions of the neutral compounds were prepared in $\mathrm{CFCl}_{3}(\mathrm{~F}-11)$ for $\mathrm{ESR}$ 
spectroscopy or in a 1:1 mixture of $\mathrm{CFCl}_{3}$ and $\mathrm{CF}_{2} \mathrm{BrCF}_{2} \mathrm{Br}^{40,41}$ for optical measurements. These solutions were placed in quartz tubes (ESR work) or special optical cuvettes ${ }^{42}$ in which they were exposed to $\approx 0.5 \mathrm{MRad}$ of ${ }^{60} \mathrm{Co} \gamma$-radiation at $77 \mathrm{~K}$.

Argon Matrix Experiments. Compounds 2 and $\mathbf{2}-\mathrm{Me}_{8}$ were premixed with a 1000-fold excess of an 85:15 mixture of $\mathrm{Ar}$ and $\mathrm{N}_{2}$ (the latter was added to improve the optical quality of matrices) and with an equimolar amount of $\mathrm{CH}_{2} \mathrm{Cl}_{2}$ which acts as an electron scavenger in the ionization step. About $10 \mathrm{mmol}$ of the gas mixture was deposited on a CsI window kept at 20 $\mathrm{K}$. After cooling to $12 \mathrm{~K}$, the matrix was exposed to $\mathrm{X}$ irradiation for $90 \mathrm{~min}$ which resulted in ca. $10 \%$ of the neutral precursors being ionized. ${ }^{42}$

Ion Recombination Fluorescence Decay. The ion recombination fluorescence was detected by single photon counting with an X-ray fluorimeter described elsewhere. ${ }^{43}$ The duration of the $20 \mathrm{keV}$ ionizing pulses and the apparatus response were both about $2.5 \mathrm{~ns}$. The light was collected with a $260-390 \mathrm{~nm}$ band-pass filter to separate the fluorescence of $p$-terphenyl that was used as luminophor. To decrease the influence of instrumental drift, the fluorescence decays were registered for periods of $250 \mathrm{~s}$, alternatively, with and without a $0.1 \mathrm{~T}$ external magnetic field (zero magnetic field was adjusted to within \pm 0.05 $\mathrm{mT}$ ).

Solvent treatment and sample preparation were performed in the same manner as reported previously. ${ }^{20,24}$ The solutions were degassed by repeated freeze-pump-thaw cycles. The temperature of the solution during measurements was stabilized within $\pm 0.5 \mathrm{~K}$, except at $>270 \mathrm{~K}$ where the accuracy was about $\pm 1 \mathrm{~K}$.

Spectroscopies. Electronic absorption (EA) spectra were measured on a Perkin-Elmer Lambda-900 spectrometer (200$2000 \mathrm{~nm}$ ). ESR spectra were taken on a Varian E9 instrument or a Bruker ESP-300 system, with the latter also serving for the ENDOR studies.

Quantum Chemical Calculations. The geometries of all species were optimized by the B3LYP density functional method using the 6-31G* basis set, both as implemented in the Gaussian 98 package of programs. ${ }^{44}$

Acknowledgment. This work is part of Project No. 2000067881.02 of the Swiss National Science Foundation. A.d.M. acknowledges support from the State of Niedersachsen and the Fonds der Chemischen Industrie. M.v.S. is indebted to the Hermann-Schlosser-Foundation for a graduate fellowship. V.I.B. acknowledges the support of the Russian Foundation of Basic Research (Grant \#05-03-32620).

\section{References and Notes}

(1) de Meijere, A. Angew. Chem., Int. Ed. Engl. 1979, 18, 809

(2) Wiberg, K. B. Introduction. In Carbocyclic Three-Membered Ring Compounds; de Meijere, A., Ed.; Thieme: Stuttgart, 1997; Vol. E 17a, p 1.

(3) Carbocyclic Three-Membered Ring Compounds; de Meijere, A., Ed.; Thieme: Stuttgart, 1997; Vol. E 17a-c.

(4) Small Ring Compounds in Organic Synthesis; de Meijere, A. Ed.; Topics in Current Chemistry 133, 135, 144, 155, 178, and 207; Springer: Berlin and Heidelberg, Germany, 1986, 1987, 1988, 1990, 1996, 2000.

(5) The Chemistry of the Cyclopropyl Group; Rappoport, Z., Ed.; Wiley: Chichester, U.K., 1987.
(6) Boche, G.; Walborsky, H. M. In Cyclopropane Derived Reactive Intermediates; Patai, S., Rappoport, Z., Eds.; John Wiley \& Sons: Chichester, U.K., 1990; pp 2-33.

(7) Friedrich, E. C. In The Chemistry of the Cyclopropyl Group; Rappoport, Z., Ed.; Wiley: Chichester, U.K., 1987; p 633.

(8) Schöllkopf, U. Angew. Chem., Int. Ed. Engl. 1968, 7, 588.

(9) Gerson, F.; de Meijere, A.; Qin, X.-Z. J. Am. Chem. Soc. 1989 111,1135

(10) Gerson, F.; Schmidlin, R.; de Meijere, A.; Späth, T. J. Am. Chem. Soc. 1995, 117, 8431 .

(11) Müller, B.; Bally, T.; Gerson, F.; de Meijere, A.; von Seebach, M. J. Am. Chem. Soc. 2003, 125, 13776

(12) de Meijere, A.; Kozhushkov, S. I.; Khlebnikov, A. F. Top. Curr. Chem. 2000, 207, 89.

(13) de Meijere, A.; Kozhushkov, S. I. Eur. J. Org. Chem. 2000, 3809

(14) de Meijere, A.; Kozhushkov, S. I.; Späth, T.; von Seebach, M.; Löhr, S.; Nüske, H.; Pohlmann, T.; Es-Sayed, M.; Bräse, S. Pure Appl. Chem. 2000, 72, 1745.

(15) Fitjer, L.; Conia, J.-M. Angew. Chem., Int. Ed. Engl. 1973, 12, 761.

(16) Eckert-Maksic, M.; Zöllner, S.; Göthling, W.; Boese, R.; Maksimovic, L.; Machinek, R.; de Meijere, A. Chem. Ber. 1991, 124, 1591.

(17) Lukin, K. A.; Zefirov, N. S.; Yufit, D. S.; Struchkov, Y. T. Tetrahedron 1992, 45, 9977.

(18) Salikhov, K. M.; Molin, Y. N.; Sagdeev, R. Z.; Buchachenko, A. L. In Spin Polarization and Magnetic Effects in Radical Reactions; Molin,

Y. N., Ed.; Elsevier: Amsterdam, 1984.

(19) Brocklehurst, B. Radiat. Phys. Chem. 1997, 50, 213.

(20) Bagryansky, V. A.; Usov, O. M.; Borovkov, V. I.; Kobzeva, T. V.; Molin, Y. N. Chem. Phys. 2000, 255, 237.

(21) Bagryansky, V. A.; Borovkov, V. I.; Molin, Y. N. Phys. Chem. Chem. Phys. 2004, 6, 924.

(22) Details about the time-resolved magnetic field effect and its semiclassical modeling are given in the Supporting Information.

(23) Schulten, K.; Wolynes, P. G. J. Chem. Phys. 1978, 68, 3292

(24) Borovkov, V. I.; Bagryansky, V. A.; Yeletskikh, I. V.; Molin, Y. N. Mol. Phys. 2002, 100, 1379.

(25) Lozovoy, V. V.; Anishchik, S. V.; Medvedev, N. N.; Anisimov, O. A.; Molin, Y. N. Chem. Phys. Lett. 1990, 167, 122.

(26) Borovkov, V. I.; Velizhanin, K. A. Chem. Phys. Lett. 2004, 394, 441

(27) See, e.g.: Werst, D. W. Chem. Phys. Lett. 1996, 251, 315.

(28) Kerr, J. A.; Smith, A.; Trotman-Dickenson, A. F. J. Chem. Soc. A 1969, 1400 .

(29) Walsh, R. Int. J. Chem. Kinet. 1970, 2, 71.

(30) Arnold, P. A.; Carpenter, B. K. Chem. Phys. Lett. 2000, 328, 90.

(31) Beckwith, A. L. J. In Rearrangments in Ground and Excited States; de Mayo, P., Ed.; Academic Press: New York, 1980; Vol. 1; p 161.

(32) Walton, J. C. In Carbocyclic Three-Membered Ring Compounds; de Meijere, A., Ed.; Thieme: Stuttgart, Germany, 1997; Vol. E 17c; p 2438.

(33) Olah, G. A.; Reddy, V. P.; Prakash, G. K. S. Chem. Rev. 1992, 92, 69.

(34) Yates, B. F.; Bouma, W. J.; Radom, L. J. Am. Chem. Soc. 1984 106,5805

(35) Fessenden, R. W.; Schuler, R. H. J. Chem. Phys. 1963, 39, 2147.

(36) Bally, T.; Hrovat, D.; Borden, W. T. Phys. Chem. Chem. Phys. 2000, 2, 3363.

(37) Williams, F. Radiat. Phys. Chem. 2003, 67, 211.

(38) Kirwan, J. N.; Roberts, B. P. J. Chem. Soc., Perkin Trans. 2 1989, 539.

(39) De Meijere, A.; Chaplinski, V.; Winsel, H.; Kuzhnetzov, M. A.; Rademacher, P.; Boese, R.; Haumann, T.; v. Schleyer, P. R.; Zywietz, T.; Jiao, P.; Merstetter, P.; Gerson, F. Angew. Chem., Int. Ed. Engl. 1999, 38, 2430 .

(40) Sandorfy, C. Can. J. Spectrosc. 1965, 85, 10

(41) Grimison, A.; Simpson, G. A. J. Phys. Chem. 1968, 72, 1776.

(42) Bally, T. In Radical Ionic Systems; Lund, A., Shiotani, M., Eds.; Kluwer: Dordrecht, The Netherlands, 1991; Vol. 6; p 3.

(43) Anishchik, S. V.; Grigoryants, V. M.; Shebolaev, I. V.; Chernousov, Y. D.; Anisimov, O. A.; Molin, Y. N. Prib. Techn. Eksp. (Russ.) 1989, 4, 74

(44) Frisch, M. J.; Trucks, G. W.; Schlegel, H. B.; Scuseria, G. E.; Robb M. A.; Cheeseman, J. R.; Zakrzewski, V. G.; Montgomery, J. A.; Stratmann, R. E.; Burant, J. C.; Dapprich, S.; Millam, J. M.; Daniels, A. D.; Kudin, K. N.; Strain, M. C.; Farkas, O.; Tomasi, J.; Barone, V.; Cossi, M.; Cammi, R.; Mennucci, B.; Pommelli, C.; Adamo, C.; Clifford, S.; Ochterski, J.; Petersson, G. A.; Ayala, P. Y.; Cui, Q.; Morokuma, K.; Malick, D. K.; Rabuck, A. D.; Raghavachari, K.; Foresman, J. B.; Cioslowski, J.; Ortiz, J. V.; Stefanov, B. B.; Liu, G.; Liashenko, A.; Piskorz, P.; Komaromi, I.; Gomperts, R.; Martin, R. L.; Fox, D. J.; Keith, T.; Al-Laham, M. A.; Peng, C. Y.; Nanayakkara, A.; Challacombe, M.; Gill, P. M. W.; Johnson, B. G.; Chen, W.; Wong, M. W.; Andres, J. L.; Gonzales, C.; Head-Gordon, M.; Repogle, E. S.; Pople, J. A.; Gaussian 98, Rev. A7-A11. Gaussian, Inc.: Pittsburgh, PA, 1998 